\title{
Research on the impact of economic growth and technological innovation on carbon emissions from the perspective of space
}

\author{
${ }^{1 \text { st }}$ Bingwen.Bao ${ }^{1 . a},{ }^{2 r d}$ Beiqiao.Lin ${ }^{2, b}$ \\ ${ }^{1}$ Sun-yat-sen University, Guangzhou City \\ ${ }^{2} \mathrm{Xi}$ 'an Jiaotong-liverpool University, Suzhou City
}

\begin{abstract}
As many economic activities have a spatial spillover effect on carbon emissions, this paper selects the data of various provinces and cities from 2003 to 2017 to construct a spatial vector autoregressive model to analyze and study the effects of economic growth and technological innovation on carbon emissions from a spatial perspective. The results of the study found that carbon emissions, economic growth, and technological innovation generally showed positive response characteristics after being impacted by each other in time, but they weakened over time. In space, carbon emissions will also increase with geographic distance, and the response received will continue to weaken.
\end{abstract}

\section{Introduction}

Global warming is the biggest environmental problem faced by the people of the world at present, and it is also a great challenge for all mankind. It is found that the main cause of global warming is a large amount of $\mathrm{CO}_{2}$ gas emitted from people's production activities. For countries with large carbon emissions, such as China, the economic growth has attracted worldwide attention, and the growth rate has been maintained at a high speed of more than $7 \%$ in the past 20 years. However, China's carbon dioxide emissions will only account for $11 \%$ of the world's total emissions by the end of the 20th century, while China's total emissions will increase by only $11 \%$ in the $1990 \mathrm{~s} .{ }^{1}$ In terms of technology, China has also made many reforms, which have also curbed carbon emissions. Therefore, it is very important to study the influence factors of carbon emissions, economic growth and technological progress, and to control the amount of carbon emissions and get environmental protection.

\section{Literature review}

At present, most scholars and practitioners think that the relationship between carbon emissions and economic growth is inverted U-shaped, and different countries and regions are in different inverted U-shaped regions. Among them, musolesi (2010) found that there is an inverted U-shaped relationship between $\mathrm{CO}_{2}$ and per capita GDP in high-income countries, while in relatively backward countries, $\mathrm{CO}_{2}$ and per capita GDP show a linear increasing trend (still in the increasing stage of inverted U-shaped curve).At the same time, Guangyu et al. (2017) studied the relationship between $\mathrm{CO}_{2}$ emissions and economic growth in G20 countries, and found that most developed countries have passed the inflection point of the inverted U-shaped curve, while many developing countries are still in the increasing stage of the inverted U-shaped curve. ${ }^{2}$

For the research on the relationship between carbon emissions and technological innovation, most of the research results basically confirm the key role of technological progress and innovation in carbon emission reduction. Copeland et al. (2003) introduced the effect of emission reduction technology in the study of the relationship between economic growth and environmental quality. The results show that emission reduction technology can promote the quality of high-income countries. However, some Chinese scholars believe that technological progress can not all improve the environment, save energy and reduce emissions. When Zhang cuiju et al. (2015) used the spatial Durbin model to study the impact of technological progress on carbon emissions, they found that there was a U-shaped relationship between technological progress and carbon emissions, that is, first inhibit and then promote carbon emissions. ${ }^{3}$

At present, there are few studies on the comprehensive relationship between the three at home and abroad. However, the academia has given that Lin Yifu (2002) further discussed the relationship among technology selection, industrial structure upgrading and economic growth, and held that under the development strategy of comparative advantage, a country should not only choose the technology that is consistent with its own resource structure, but also consider the comparative advantage of enterprises in the upgrading of industrial structure and technology selection. Chen Shengming et al. (2016)

abaobingwen5518@163.com, bBeiqiao.Lin18@xjtlu.edu.cn 
empirically tested the spatiotemporal transmission effect between technology selection, industrial structure upgrading and economic growth in China, and found that most of them showed positive response characteristics after being impacted by each other. ${ }^{4}$

From the existing research of the above scholars, it can be found that the current research on the impact of carbon emission on environmental quality mainly focuses on the impact of economic growth or technological innovation on a single explanatory variable, and the research is not much under the common influence of the two; at the same time, there is a lack of impact analysis on the comprehensive effects of time and space. In this paper, on the basis of relevant theories, combined with economic growth and technological innovation, we use spatial vector autoregressive model and impulse response of each variable to study its impact on carbon emissions.

\section{Empirical model and data explanation}

\subsection{Data sample description}

This paper selects the panel data of 30 provinces (cities and autonomous regions) in China from 2003 to 2017 (Tibet is not included in the study due to the lack of data). The following are the data processing explanations of the variables: (1) carbon emissions: carbon emissions refer to the average greenhouse gas emissions generated in the production, transportation, use and recovery of the product, and the most important substance in greenhouse gases is $\mathrm{CO}_{2}$, According to the formula for calculating carbon dioxide emissions in the carbon emissions trading network, we use the actual energy consumption per year multiplied by the carbon intensity coefficient of each energy source. ${ }^{5}$

(2) Economic Growth: measure the real economic growth rate by logarithm of real GDP.(3) Technological progress: R\&D refers to the human, material and financial resources necessary for scientific research and experimental development activities. R\&D expenditure and its proportion in GDP are important indicators to measure the scale of science and technology activities and the level of science and technology input in a country. Therefore, we choose R\&D funds to measure technological progress. At the same time, in order to eliminate the influence of heteroscedasticity, the variables are treated by logarithm.

\subsection{Model construction}

Spatial vector autoregressive model is an endogenous system that considers both time and space factors. Referring to Ye Azhong's (2015) model analysis method, this paper introduces the time lag period and spatial lag period of all variables as independent variables, and constructs the spatial vector autoregressive model as shown in the following formula $(1)^{6}$

$$
Y_{\mathrm{knt}}=u_{k n}+\sum_{i=1}^{K}\left(\alpha_{k i} Y_{\mathrm{int}}+\beta_{k j} Y_{\mathrm{int}-1}+\theta_{k i} Y_{\mathrm{int}} *+\lambda_{k i} Y_{\mathrm{int}-1} *\right)+\varepsilon_{k n t}
$$

Among them: $Y_{\text {knt }}$ The first subscript of represents the $\mathrm{kth}$ endogenous variable, $\mathrm{k}=1,2, \cdots, K$ The second subscript is $\mathrm{n}, n=1,2, \cdots, N$ The third subscript represents time t, $t=1,2, \cdots, T ; Y_{\text {int-1 }}$ Is the time lag term, $Y_{\text {int-1 }}^{*}=W Y_{\text {int-1 }}$ Represents the spatial lag term, $W=\left(w_{i j}\right), i, j=1,2, \ldots, N$ Is a weight matrix in which the elements $w_{i j}$ Are known and diagonal elements $w_{i i}=0$ 。 $u_{k n}, \alpha_{k i}, \beta_{k j}, \theta_{\mathrm{ki}}, \lambda_{k i}$ is the parameter to be estimated.

Equation (1) can also be used $K \times K$ matrix $A 、 B 、 \Theta 、 \Lambda$ To replace $\alpha_{\mathrm{ki}} 、 \beta_{\mathrm{kj}} 、 \theta_{\mathrm{ki}} 、 \lambda_{\mathrm{ki}}$ Write the above formula in the form of matrix

$$
Y_{\mathrm{t}}=u+A^{*} Y_{t}+B^{*} Y_{t-1}+\Theta * Y_{t}^{*}+\Lambda * Y_{t-1} *+\varepsilon_{t}
$$

among $Y 、 u$ yes $N K \times 1$ Column vector of, $A^{*}=I_{N} \otimes A, B^{*}=I_{N} \otimes B, \Lambda^{*}=I_{N} \otimes \Lambda$ It's all in pieces $N K \times N K$ Matrix.

According to the selected variables and the introduction of the above model, the spatial vector autoregressive model with $\mathrm{CO} 2$, GDP and RD as endogenous variables is constructed as follows:
On the left side of the model $\ln C O_{2 i t} 、 \ln G D P_{i t}$ 、 $\ln R D_{i t}$ Carbon emissions, economic growth and technological progress, on the right $\ln C \mathrm{O}_{2 i t-1}$ 、 $\ln G D P_{i t-1} 、 \ln R D_{i t-1}$ is the time lag term of the explained variable, $\ln C O_{2 i t-1}^{*}$ 、 $\ln G D P_{i t-1}^{*}$ 、 $\ln R D_{i t-1}^{*}$ Is the spatial lag period term of the explained variable. $\beta_{i j}$ Represents the coefficient of the $\mathrm{j}$ th time lag period $\left.\begin{array}{ll}\lambda_{12} & \lambda_{13} \\ \lambda_{22} & \lambda_{23} \\ \lambda_{32} & \lambda_{33}\end{array}\right]\left[\begin{array}{c}\ln C O_{2 i t-1}^{*} \\ \ln G D P_{i t-1}^{*} \\ \ln R D_{i t-1}^{*}\end{array}\right]+\left[\begin{array}{c}\Phi_{1 i} \\ \Phi_{2 i} \\ \Phi_{3 i}\end{array}\right]+\left[\begin{array}{l}u_{1 t} \\ u_{2 t} \\ u_{3 t}\end{array}\right]+\left[\begin{array}{c}\varepsilon_{1 t} \\ \varepsilon_{2 t} \\ \varepsilon_{3 t}\end{array}\right]$

variable to the $\mathrm{I}$ th variable; $\lambda_{i j}$ Represents the coefficient of the $\mathrm{j}$ th spatial lag period variable to the I th variable. $\Phi_{1 i} 、 \Phi_{2 i} 、 \Phi_{3 i}$ The third variable is the influence of fixed individual; $u_{1 t} 、 u_{2 t}, u_{3 t}$ They are expressed as the time fixed effects of the first, second and third variables; $\varepsilon_{1 t} 、 \varepsilon_{2 t} 、 \varepsilon_{3 t}$ They are expressed as the spatial error terms of the first, second and third variables. 


\section{Econometric testing and empirical model construction}

\subsection{Metrological Inspection}

\subsubsection{Stability test}

In order to avoid the results of pseudo regression, the stationarity of each variable must be tested. In the case of assuming the existence of intercept term, according to the test results of LLC method, it is found that each variable refuses the original hypothesis of "unit root exists" at the significance level of $1 \%$, so it can be considered that each variable has good stability.

Table 1 stability test table

\begin{tabular}{ccccc}
\hline variable & Inspection type $(\mathrm{C}, \mathrm{t}, \mathrm{K})$ & LLC statistics & P value & result \\
\hline $\ln \mathrm{CO}_{2}$ & $(\mathrm{C}, 0,1)$ & -21.264 & 0.000 & stable \\
$\ln \mathrm{GDP}$ & $(\mathrm{C}, 0,1)$ & -17.841 & 0.000 & stable \\
$\operatorname{lnRD}$ & $(\mathrm{C}, 0,1)$ & -18.162 & 0.000 & stable \\
\hline
\end{tabular}

\subsubsection{Spatial correlation test}

Before the establishment of spatial data model, it is necessary to test the spatial correlation. According to
Moran's I test results, Moran's I standard statistics of all variables are significantly greater than 0 at the significance level of $1 \%$. It shows that there is a significant spatial correlation between the variables

Table 2 spatial correlation table

\begin{tabular}{cccccc}
\hline variable & $\mathrm{I}$ & $\mathrm{E}(\mathrm{I})$ & $\mathrm{sd}(\mathrm{I})$ & $\mathrm{z}$ & $\mathrm{p}$-value \\
\hline $\ln \mathrm{CO}_{2}$ & 0.411 & -0.002 & 0.034 & 12.111 & 0.000 \\
$\ln \mathrm{GDP}$ & 0.188 & -0.002 & 0.034 & 5.595 & 0.000 \\
$\operatorname{lnRD}$ & 0.426 & -0.002 & 0.034 & 12.554 & 0.000 \\
\hline
\end{tabular}

\subsubsection{Granger causality test}

After the stationarity test, it is necessary to make Granger causality test between and three variables to determine the effect of time lag on the explained variables. From the test results, at the $5 \%$ significance level, except $\mathrm{CO}_{2}$ is not the Granger cause of $\mathrm{RD}$, the relationship among the other three variables at the $5 \%$ significance level rejects the original hypothesis that it is not the Granger cause of the other party. This shows that the time lag of GDP and R \& $\mathrm{D}$ has a good effect on $\mathrm{CO}_{2}$.

Table 3 Granger causality test table

\begin{tabular}{cccc}
\hline Null Hypothesis & Obs & F-Statistic & Prob. \\
\hline RD does not Granger Cause GDP & 390 & 8.501 & 0.000 \\
GDP does not Granger Cause RD & 390 & 29.603 & 0.000 \\
CO2 does not Granger Cause GDP & 390 & 3.815 & 0.023 \\
GDP does not Granger Cause CO 2 & 390 & 21.516 & 0.000 \\
CO2 does not Granger Cause RD & 390 & 2.554 & 0.079 \\
RD does not Granger Cause $\mathrm{CO}_{2}$ & 390 & 21.184 & 0.0 \\
\hline
\end{tabular}

\subsection{Empirical analysis}

Regression results of spvar model

Table 4 result table of spatial vector autoregression

\begin{tabular}{cccc}
\hline & $\operatorname{lnCO}_{2}$ & $\operatorname{lnGDP}$ & $\operatorname{lnRD}$ \\
\hline $\operatorname{lnCO2(-1)}$ & $0.058(0.082)$ & $0.125(0.143)$ & $-0.001(0.059)$ \\
$\operatorname{lnGDP(-1)}$ & $0.026(0.068)$ & $-0.124(0.118)$ & $0.044(0.049)$ \\
$\operatorname{lnRD(-1)}_{\operatorname{lnCO2}^{*}(-1)}$ & $0.177(0.148)$ & $0.188(0.259)$ & $0.200(0.108)$ \\
$\operatorname{lnGDP}^{*}(-1)$ & $0.173(0.123)$ & $0.074(0.175)$ & $0.008(0.088)$ \\
$\operatorname{lnRD}^{*}(-1)$ & $0.020(0.102)$ & $0.688(0.145)$ & $0.133(0.073)$ \\
& $-0.233(0.223)$ & $0.542(0.317)$ & $0.157(0.159)$ \\
\hline
\end{tabular}


From the significance of the coefficient of time-space lag term, it is enough to explain the rationality of adding space term in the research process. By observing the coefficients of explanatory variables, it is found that the current carbon emissions of each region are positively affected by the past carbon emissions, GDP growth rate and R \& D (the coefficients are all positive), among which R \& D has the greatest impact; at the same time, it is also affected by the carbon emissions, GDP growth rate and R \& D of other regions in the past, The growth rate of GDP has a positive impact on carbon emissions, while R \& D has a negative impact.

\subsection{Impulse response analysis}

Due to the large number of spatial individuals and large amount of data, it is impossible to analyze the response modes of 30 regions in China. Therefore, this paper selects Beijing, the political center and carbon emission City, as the representative sample (impact source), selects Tianjin, Hebei, economic center Shanghai and Guangdong as the research objects to conduct impulse response analysis.

\subsection{Impact of carbon emissions}

It can be seen from the figure that under the positive impact of one standard deviation of energy carbon emissions in Beijing, Tianjin and Hebei, the energy carbon emissions in Beijing, Tianjin and Hebei have a significant positive response at the beginning, while the impact on the energy carbon emissions of Shanghai and Guangdong is relatively small; at the same time, in terms of economic growth, Beijing, Tianjin and Hebei regions have begun to produce obvious positive responses, The results show that the increase of carbon emissions in Beijing has a positive effect on the economic growth of these regions, but has little impact on the economic growth of Shanghai and Guangdong; in terms of R \& D, Beijing has an obvious positive response, while Tianjin and Hebei regions have begun to produce a negative effect, and then have a positive effect. For Shanghai and Guangdong, the impact of technological progress is small.

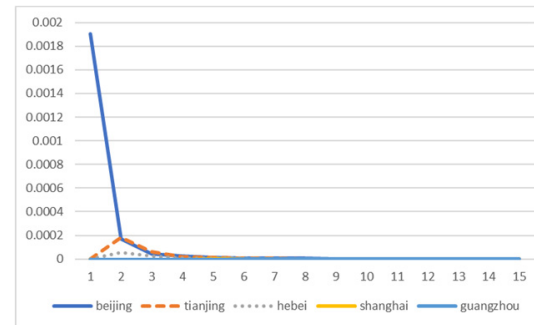

Figure 1 (1) impact of Beijing's carbon emissions on regional carbon emissions

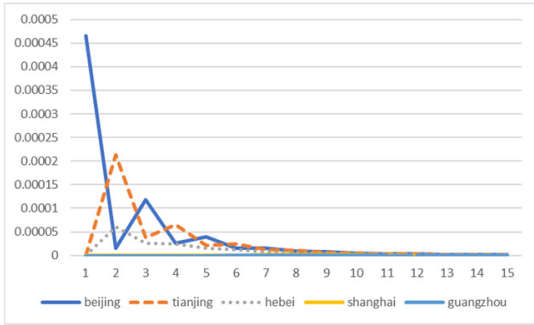

Figure 1 (2) the impact of carbon emissions on regional economic growth in Beijing

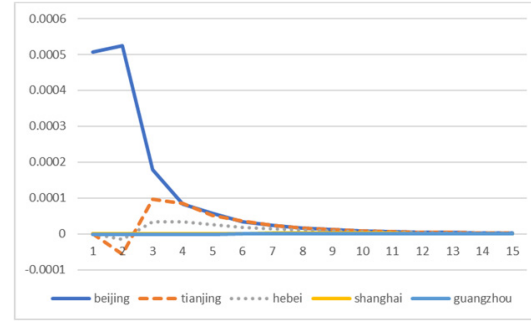

Figure 1 (3) impact of Beijing's carbon emissions on technological progress in various regions

\subsection{Impact of economic growth}

It can be seen from the figure that under the positive impact of a standard deviation of economic growth in Beijing, the energy carbon emissions of Beijing, Tianjin and Hebei have an obvious positive response at the beginning, while the impact on energy carbon emissions in Shanghai and Guangdong is relatively small; at the same time, in terms of economic growth, Beijing, Tianjin and Hebei have all produced obvious positive responses, but the impact has disappeared rapidly,In terms of R \& D, Beijing, Tianjin and Hebei all had obvious positive response, and lasted for a long time. For Shanghai, Guangdong's R \& D impact was small, indicating that economic growth has an obvious role in promoting technological progress.

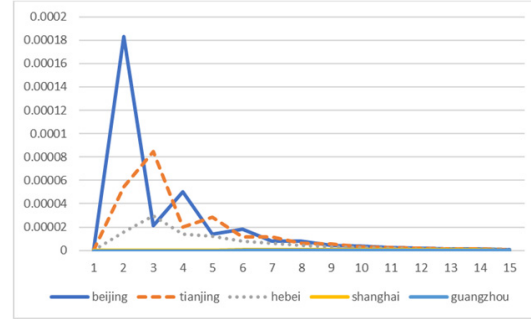

Figure 2 (1) impact of Beijing's economic growth on regional carbon emissions

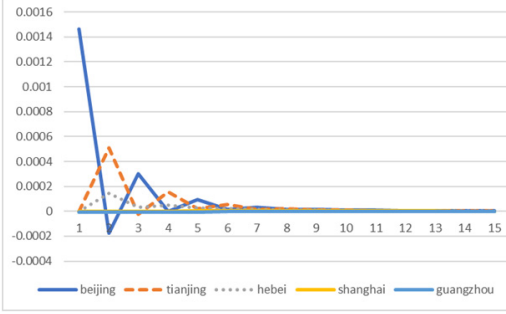

Figure 2 (2) the impact of Beijing's economic growth on regional economic growth

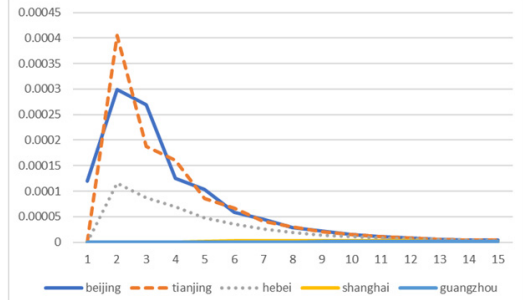

Figure 2 (3) the impact of Beijing's economic growth on technological progress in various regions 


\section{Impact of technological progress}

It can be seen from the figure that under the positive impact of a standard deviation of R \& D in Beijing, the energy carbon emissions in Tianjin and Hebei both have an obvious positive response at the beginning, but the carbon emissions in Beijing have a negative impact, and then have a positive impact. For Shanghai and Guangdong, there are also some positive effects. At the same time, in terms of economic growth, Beijing has a positive impact on energy carbon emissions, In terms of R \& D, Beijing, Tianjin and Hebei have a significant positive response, and for Shanghai, Guangdong's economic growth has a small impact; in terms of $\mathrm{R} \& \mathrm{D}$, Beijing, Tianjin and Hebei have a significant positive response, which lasts for a long time. For Shanghai, Guangdong's R \& D has a small impact, indicating that economic growth has an obvious role in promoting technological progress.

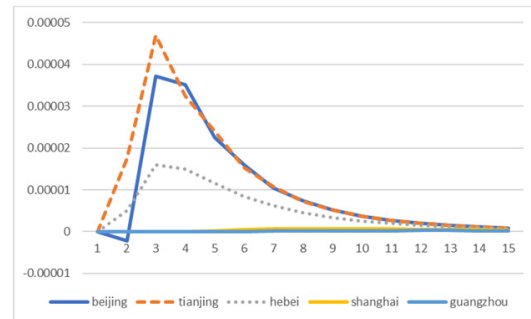

Figure 3 (1) impact of Beijing's technological progress on regional carbon emissions

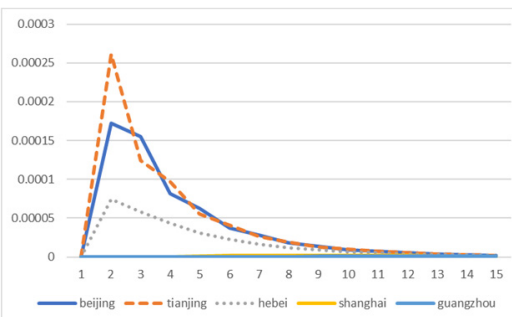

Figure 3 (2) the impact of Beijing's technological progress on regional economic growth

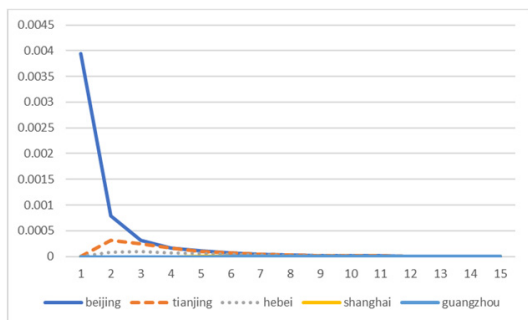

Figure 3 (3) the impact of Beijing's technological progress on regional technological progress

\section{Conclusion and Enlightenment}

Environmental protection is a serious problem faced by people at present. Based on this, this paper constructs a spatial vector autoregressive model with energy carbon emissions as the explanatory variable, technological progress and economic growth as explanatory variables. Based on the coefficient estimation of each parameter obtained by spvar model, the research objects are Beijing Tianjin Hebei region, Shanghai and Guangdong Province, The impulse response function is used to simulate the spatial impact and response path of technological progress, economic growth and energy carbon emissions with Beijing as the shock source and Beijing Tianjin Hebei region, Shanghai and Guangdong as the shock objects.

According to the regression results of spvar model, the current carbon emissions of each region are positively affected by the past carbon emissions, GDP growth rate and R \& D; at the same time, they are also affected by the positive impact of carbon emissions, GDP growth rate and $\mathrm{R} \& \mathrm{D}$ in other regions in the past. Therefore, technological progress in other regions will inhibit the carbon emissions in this region. However, other factors will promote the regional carbon emissions (the past carbon emissions of other regions have a greater impact on the past technological progress of the region); from the result of economic growth and technological progress on carbon emissions, we can see that the relationship between China's current carbon emissions and economic growth and technological progress is still on the left side of the inverted U-shaped curve.

According to the impulse response results, under the positive impact of standard deviation of energy carbon emission, economic growth and R \& D in Beijing, the energy carbon emissions of Beijing, Tianjin and Hebei all have obvious positive response at the beginning, while for Shanghai and Guangdong, the impact is small, At the same time, for some provinces which are far away from
Beijing, we also found that the impact of carbon emissions is smaller, which indicates that the carbon emissions in the regions with close geographical location in space will be more affected; in terms of time, we find that the response is more intense at the beginning, decreases with the passage of time, and finally tends to zero.

Based on the empirical analysis, the paper gives the following suggestions

1.Compared with economic growth and carbon emissions, the impact of technological progress in the region on today's carbon emissions is smaller, indicating that the impact of technological growth on carbon emissions is smaller, and the region cannot sacrifice technological progress in order to control carbon emissions. Due to the mutual promotion between technological progress and economic growth, the feasibility of restraining them is not high, and the carbon emission levels of neighboring provinces and cities are highly correlated. Therefore, the region can consider cooperation with other regions with closer geographical location, so as to play the regional synergy effect and realize the overall green development better. ${ }^{7}$

2.Due to the developed industries in economically developed areas, carbon emissions are large. For these cities with high industrial development level, we can attract foreign investment, play their "demonstration effect" and "technology spillover" role, or accelerate the pace of industrial restructuring to develop the tertiary industry, so as to reduce the proportion of industry in the total economic output to reduce carbon emissions.

3.Carbon emission is also closely related to the behavior of enterprises. The government should introduce more policies to encourage enterprises to carry out environmental protection research and development, and give preferential treatment to technology intensive and cleaner production enterprises, so as to guide the resources in the industry to resource-saving and environment-friendly enterprises. ${ }^{8}$ 


\section{Reference}

1. Chen Jie. Research on the correlation between technological innovation, carbon emissions and economic growth in my country[J]. Statistics and Decision, 2019,35(22), pp.126-130.

2. Gao Jing. Research on the Spatial Spillover Effects and Influencing Factors of China's Inter-provincial Carbon Emissions[D]. Southwestern University of Finance and Economics, 2019.

3. Wu Jigui, Ye Azhong. The spatial shock effects of capital accumulation, economic growth and energy carbon emissions: a study based on the SSpVAR model[J]. Science of Science and Management of Science and Technology, 2016, 37(05), pp.24-33.

4. Chen Shengming, Zhang Yabin, Chen Xiaoling. Technology Choice, Industrial Structure Upgrade and
Economic Growth_-A Research Based on Semiparametric Space Panel Vector Autoregressive Model [J]. Economic Survey, 2017, 34(05), pp.87-92.

5. Yuan $\mathrm{J}, \mathrm{Xu} \mathrm{Y}, \mathrm{Hu} \mathrm{Z}$. Peak energy consumption and $\mathrm{CO} 2$ emissions in China[J]. Energy Policy, 2014,68(5), pp.508-523.

6. Sather C, Qu J S, Wang Q. Carbon Inequality at the Sub-national scale: A Case Study of Provincial-level Inequality in CO2 Emissions in China 1997-2007[J]. Energy Policy,2011(9), pp.5420-5428

7. Groot, L. Carbon Lorenz Curves[J]. Resource and Energy Economics,2010(32), pp.45-64.

8. Abdul Jalil, Mete Feridun. The Impact of Growth, Energy and Financial Development on the Environment in China: A Cointegration Analysis[J]. Energy Economics,2010(2), pp.284-291. 